\title{
Author Correction: The plant ESCRT component FREE1 shuttles to the nucleus to attenuate abscisic acid signalling
}

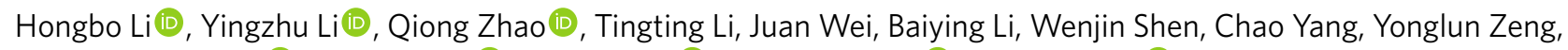

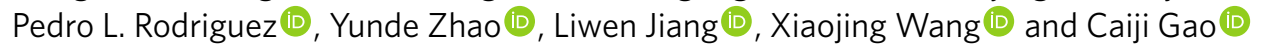

Correction to: Nature Plants https://doi.org/10.1038/s41477-019-0400-5, published online 8 April 2019.

In Fig. $2 \mathrm{~h}$ of this Article originally published, the WT (mock condition) image was mistakenly a duplicate of the free1-ctmut/GFP-tagged FREE1( $\triangle$ FYVE) (mock condition) image shown in Fig. 1f. The quantification of chlorophyll content was originally performed using the correct leaves as shown in the corrected image below. None of the scientific findings or conclusions of the paper have been affected, and the error has now been corrected.
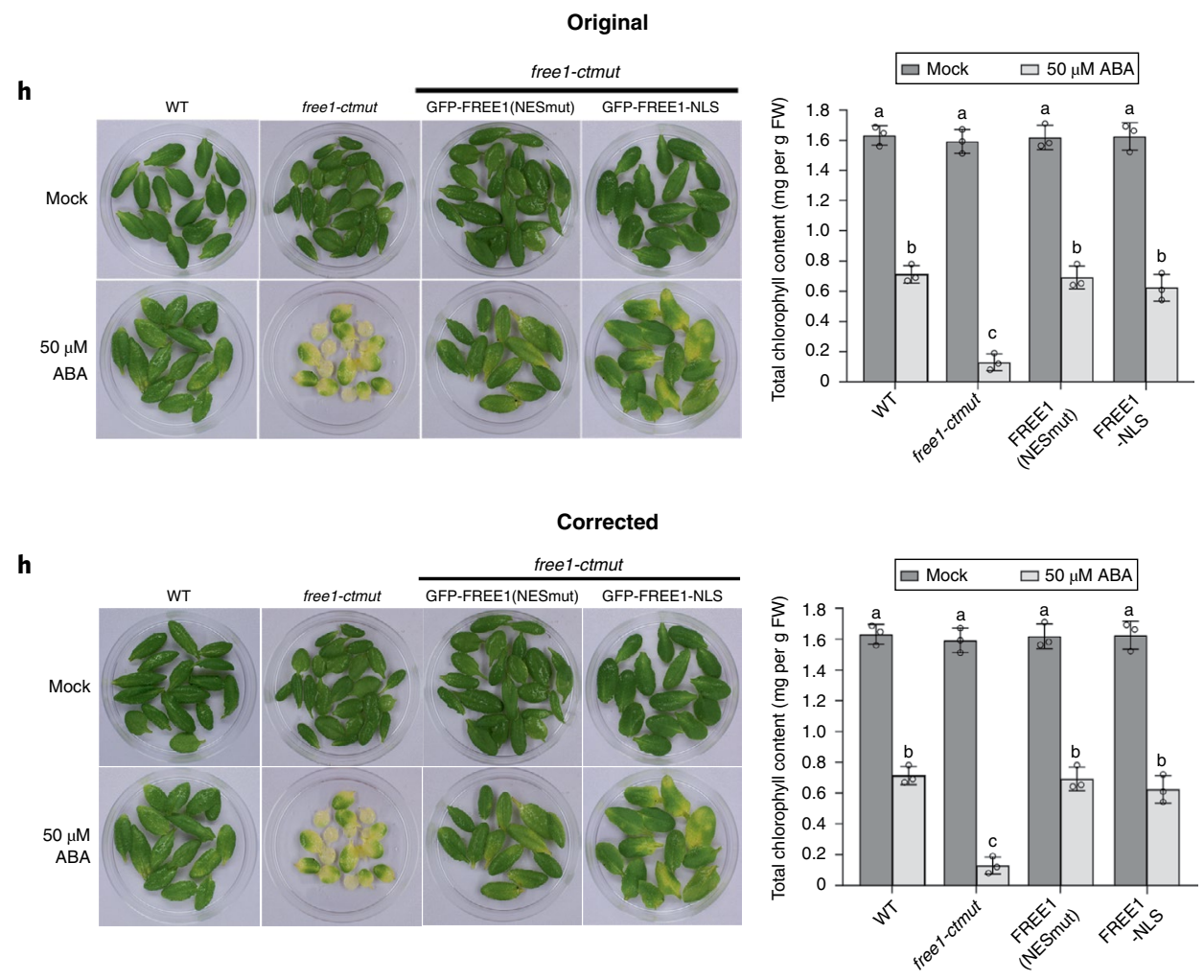

Fig. $\mathbf{2 h}$ | Original and corrected.

Published online: 20 July 2021

https://doi.org/10.1038/s41477-021-00984-0

(c) The Author(s), under exclusive licence to Springer Nature Limited 2021 